\title{
《Research Note» \\ Physiological Relationships of the Middle and Late Post-Hatch Performance of Broilers to their Embryo and Eggshell Characteristics ${ }^{1,2}$
}

\author{
Radhakrishna Pulikanti ${ }^{1}$, Edgar D. Peebles ${ }^{1}$, Lloyd W. Bennett ${ }^{2}$, Wei Zhai ${ }^{1}$ and Patrick D. Gerard ${ }^{3}$ \\ ${ }^{1}$ Department of Poultry Science, Mississippi State University, Mississippi State, Mississippi, 39762, USA \\ ${ }^{2}$ College of Veterinary Medicine, Mississippi State University, Mississippi State, Mississippi, 39762, USA \\ ${ }^{3}$ Department of Mathematical Sciences, Clemson University, Clemson, SC 29634, USA
}

\begin{abstract}
Relationships between physiological variables of middle and late post-hatch broilers with their corresponding egg and embryo variables were examined. Sixty Ross $\times$ Ross 708 broiler hatching eggs were randomly set on each of 8 replicate tray levels of an incubator. On $10.5 \mathrm{~d}$ of incubation, transponders were implanted in the air cells of 4 embryonated eggs per replicate for determination of internal egg temperature $\left(\mathrm{T}_{\mathrm{emb}}\right)$ through $\mathrm{d} 18.5$. On $\mathrm{d} 18.5$, the implanted embryonated eggs were transferred to a hatcher unit where they were monitored for hatch every $12 \mathrm{~h}$. Incubation length, eggshell water vapor conductance $\left(\mathrm{G}_{\mathrm{H} 2 \mathrm{O}}\right)$, specific $\mathrm{G}_{\mathrm{H} 2 \mathrm{O}}\left(\mathrm{g}_{\mathrm{H} 2 \mathrm{O}} ; \mathrm{G}_{\mathrm{H} 2 \mathrm{O}}\right.$ adjusted to a $100 \mathrm{~g}$ set egg weight basis), and $\mathrm{G}_{\mathrm{H} 2 \mathrm{O}}$ constants $\left(\mathrm{K}_{\mathrm{H} 2 \mathrm{O}}\right)$ of the embryonated eggs were determined. Chicks were placed in corresponding replicate floor pens and were grown out from 0 ( $21.5 \mathrm{~d}$ of incubation) to $48 \mathrm{~d}$ of age. On 28 and $48 \mathrm{~d}$ post-hatch, approximately 2 birds per pen were necropsied for determination of BW, and the relative weights and moisture concentrations of their liver, breast muscle, and left gastrocnemius muscle. Breast muscle moisture concentration on d 28 was negatively correlated with $\mathrm{G}_{\mathrm{H} 2 \mathrm{O}}, \mathrm{g}_{\mathrm{H} 2 \mathrm{O}}$, and $\mathrm{K}_{\mathrm{H} 2 \mathrm{O}}$, and breast muscle moisture concentration on d 48 was negatively correlated with incubation length. However, relative body and breast muscle weights on d 48 were positively correlated with $\mathrm{g}_{\mathrm{H} 2 \mathrm{O}}$ and $\mathrm{K}_{\mathrm{H} 2 \mathrm{O}}$, and relative $\mathrm{BW}$ on $\mathrm{d} 48$ was positively correlated with incubation length. More importantly, relative breast muscle weight on $\mathrm{d} 48$ post-hatch was negatively correlated with $\mathrm{T}_{\mathrm{emb}}$. The variables $\mathrm{T}_{\mathrm{emb}}, \mathrm{G}_{\mathrm{H} 2 \mathrm{O}}, \mathrm{g}_{\mathrm{H} 2 \mathrm{O}}$, and $\mathrm{K}_{\mathrm{H} 2 \mathrm{O}}$ may differentially influence the physiological variables in birds during the middle and late post-hatch grow out periods, and bird metabolic and hydration statuses may be adjusted later during the post-hatch period, so that bird BW will eventually reach its genetically predetermined level.
\end{abstract}

Key words: broiler, eggshell conductance, embryo temperature, post-hatch, transponder

J. Poult. Sci., 50: 375-380, 2013

\section{Introduction}

Approximately one third of a broiler's life is spent inside the egg as an embryo, and the factors that influence embryonic life may have an impact on overall broiler processing yield. Therefore, an examination of relationships between pre- and post-hatch physiological variables may be critical

Received: January 16, 2013, Accepted: February 26, 2013

Released Online Advance Publication: April 25, 2013

Correspondence: E.D. Peebles, Department of Poultry Science, Mississippi

State University, Mississippi State, Mississippi, 39762, United States of America. (E-mail: dpeebles@poultry.msstate.edu)

${ }^{1}$ This is Journal Article Number J-12137 from the Mississippi Agricultural and Forestry Experiment Station supported by MIS-322270.

${ }^{2}$ Use of trade names in this publication does not imply endorsement by Mississippi Agricultural and Forestry Experiment Station of these products, nor similar ones not mentioned. for the optimization of broiler productivity. The existence of relationships between incubation temperature (Lourens et al., 2005; Yalcin et al., 2005; Hulet et al., 2007; Leksrisompong et al., 2007; Molenaar et al., 2011a; Willemsen et al., 2011) and relative humidity (Bruzual et al., 2000a, b) on embryonic and post-hatch broiler development have been reported in earlier research work. Similarly, several researchers have previously suggested that set egg weight (Pinchasov, 1991; Vieira and Moran, 1999; Moran, 2007; Wolanski et al., 2007; Abiola et al., 2008), egg nutritional composition (Moran, 2007), yolk sac nutrient utilization by embryo (Murakami, 1992), eggshell temperature (Lourens et al., 2005; Molenaar et al., 2011b), incubational oxygen (Onagbesan et al., 2007; Celen et al., 2009) and $\mathrm{CO}_{2}$ concentrations (Everaet et al., 2007; Onagbesan et al., 2007; Willemsen et al., 2008), incubation length (van de Ven et al., 2011), and incubational egg weight loss (Peebles et al., 2005) may also have an effect 
on broiler embryogenesis and post-hatch growth and development.

In many of the studies discussed earlier, an examination of the influence of various treatments imposed during incubation on overall broiler post-hatch performance was limited to within $48 \mathrm{~h}$ post-hatch. In a companion article, effects of pre-hatch physiological variables such as egg internal temperature and eggshell water vapor conductance on the posthatch broiler growth and performance of corresponding chicks through $3 \mathrm{~d}$ of age were presented by Pulikanti et al. (2012b). Except for the aforementioned report by Pulikanti et al. (2012b), no studies have been previously conducted to individually examine the relationships of the characteristics of eggs and the embryos they contain with the post-hatch characteristics of the respective birds that hatched from those specific eggs. Although there have been previous reports indicating that eggshell porosity (Tullett and Burton, 1982) or eggshell water vapor conductance $\left(\mathrm{G}_{\mathrm{H} 2 \mathrm{O}} ; \mathrm{mg} \mathrm{H} \mathrm{H}_{2} \mathrm{O}\right.$ /d/Torr; Hocking, 2009) may influence broiler embryo metabolism, growth, and development, information is lacking regarding the influence of $\mathrm{G}_{\mathrm{H} 2 \mathrm{O}}$ on the middle and late post-hatch performance of broilers that hatched from those specific eggs.

An in-depth understanding of the relationships between pre- and post-hatch physiological variables is critical for the improvement of broiler incubational and post-hatch grow out management practices so as to achieve optimal broiler processing yield (Bamelis et al., 2005; Peebles et al., 2005). Therefore, the current experiment was conducted on progeny from a Ross 708 broiler breeder flock, to examine specific relationships of egg and embryonic variables, such as embryonated egg internal (air cell) temperature $\left(\mathrm{T}_{\mathrm{emb}}\right)$, incubation length (IL), $\mathrm{G}_{\mathrm{H} 2 \mathrm{O}}$, specific $\mathrm{G}_{\mathrm{H} 2 \mathrm{O}}\left(\mathrm{g}_{\mathrm{H} 2 \mathrm{O}} ; \mathrm{G}_{\mathrm{H} 2 \mathrm{O}}\right.$ adjusted to a $100 \mathrm{~g}$ set egg weight basis) and $\mathrm{G}_{\mathrm{H} 2 \mathrm{O}}$ constant $\left(\mathrm{K}_{\mathrm{H} 2 \mathrm{O}}\right)$, with broiler growth and developmental characteristics through the middle and late terms of the post-hatch grow out period.

\section{Materials and Methods}

\section{General}

The current experimental protocol was approved by the Institutional Animal Care and Use Committee of Mississippi State University. Ross $\times$ Ross 708 broiler hatching eggs were collected from a 30-wk-old breeder flock, and were held under standard storage conditions for $3 \mathrm{~d}$ before setting.

\section{Incubation}

On $\mathrm{d} 0$ of incubation, the eggs that weighed within $\pm 10 \%$ of the mean weight of all eggs collected and those that were not contaminated or visibly abnormal were incubated. Sixty eggs were randomly labeled and weighed to record their set egg weights, and were then set on each of 8 replicate tray levels (480 total eggs) of a Jamesway Model 500 single stage incubator (Jamesway Incubator Company, Inc., Cambridge, ON, Canada). The eggs were evenly distributed among the 8 central trays to ensure even air flow among all eggs (Pulikanti et al., 2012b) and they were incubated for $18 \mathrm{~d}$ under standard commercial conditions at $37.5^{\circ} \mathrm{C}$ dry bulb and $28.8^{\circ} \mathrm{C}$ wet bulb temperatures.

\section{Transponder Implantation}

On d 10.5 of incubation, the eggs were weighed and candled, and those containing slanted air cells were discarded. Subsequently, on each tray level, 4 embryonated eggs were randomly selected and the air cells of those eggs were implanted with a pre-calibrated temperature transponder (IPTT300; Bio Medic Data Systems, Inc., Seaford, DE) for determination of $\mathrm{T}_{\mathrm{emb}}$. Transponders were implanted in the air cells of 2 unfertilized eggs and these were positioned within $5 \mathrm{~cm}$ from each implanted egg on each tray level for determination of unfertilized egg internal (air cell) temperature. Furthermore, 2 sealed water filled plastic vials $(10 \mathrm{~mL}$ capacity), each containing a transponder, were positioned within $5 \mathrm{~cm}$ from each implanted embryonated and unfertilized egg for determination of external microenvironment egg temperature (Pulikanti et al., 2011b; Pulikanti et al., 2012a, b). The materials and procedures used for transponder implantation and temperature data recording in this experiment were as previously described by Pulikanti et al. (2011a, b; 2012a, b).

\section{Hatch Monitor}

On d 18.5 of incubation, each implanted embryonated egg was candled, and the eggs that contained live embryos were placed in individual hatching baskets that were specifically labeled according to egg numbers. The hatching baskets were subsequently transferred to their corresponding tray levels in a Jamesway Model 500 single stage hatcher unit (Jamesway Incubator Company, Inc., Cambridge, ON, Canada). The eggs in the hatcher were maintained at approximately $36.1^{\circ} \mathrm{C}$ dry bulb and $27.6^{\circ} \mathrm{C}$ wet bulb temperatures, and were individually monitored for hatch (hatch rate) every $12 \mathrm{~h}$ through $\mathrm{d} 21.5$ of incubation. Hatchability on $\mathrm{d}$ 21.5 of incubation, as a percentage of total eggs set and as a percentage of fertilized eggs, was also determined.

\section{Data Collection}

Embryo survivability was determined by candling eggs on d 18.5 of incubation, and was further confirmed based on hatch success through d 21.5 of incubation (Pulikanti et al., 2011b). Between 0 and $18 \mathrm{~d}$ of incubation, incubator dry and wet bulb temperature readings, and the ambient atmospheric pressure values were recorded every $12 \mathrm{~h}$. Moreover, between 0 and $18 \mathrm{~d}$ of incubation, incubator data logger temperature readings were recorded every $5 \mathrm{~min}$ using precalibrated wireless data loggers (Model TX7U; La Crosse Technology, La Crescent, MN; Pulikanti et al., 2011b; Pulikanti et al., 2012a, b). Furthermore, between 10.5 and $18.0 \mathrm{~d}$ of incubation, temperature readings were recorded every $12 \mathrm{~h}$ from transponders contained within water vials, unfertilized eggs, and embryonated eggs for the determination of external microenvironment egg temperature, unfertilized egg internal temperature, and $\mathrm{T}_{\mathrm{emb}}$, respectively. Moreover, between 0 and $21.5 \mathrm{~d}$ of incubation, incubator temperature and relative humidity readings were recorded twice daily, and incubator data logger temperature and relative humidity readings (from 3 data loggers placed equidistantly inside the incubator; Pulikanti et al., 2011a; Pulikanti et al., 2012a, b) were recorded every $5 \mathrm{~min}$. 


\section{Eggshell Water Vapor Conductance}

Average daily incubational weight (moisture) loss values of embryonated and unfertilized eggs between 10.5 and 18.0 $\mathrm{d}$ of incubation were determined for the subsequent calculation of the respective average daily percentage incubational egg weight loss (\%EWL) values. Mean values of $\mathrm{G}_{\mathrm{H} 2 \mathrm{O}}$ and $\mathrm{g}_{\mathrm{H} 2 \mathrm{O}}$ of embryonated and unfertilized eggs were calculated using the procedures and equations described by Ar et al. (1974) and Ar and Rahn (1978) and modified by Pulikanti et al. (2011b). Based on the hatch monitor data every $12 \mathrm{~h}$ between 18.5 and $21.5 \mathrm{~d}$ of incubation, IL (d) of individual embryonated eggs was determined. Furthermore, the $\mathrm{K}_{\mathrm{H} 2 \mathrm{O}}$ of the embryonated eggs were calculated by using a formula described by Ar et al. (1974) and Ar and Rahn (1978).

\section{Post-hatch Grow Out}

On d 0 post-hatch (d 21.5 of incubation), the live chicks (at least 2 chicks per tray level) that hatched from the implanted eggs were specifically labeled according to their eggs of origin, and were subsequently used for post-hatch grow out. The chicks were grown out between 0 and $48 \mathrm{~d}$ post-hatch on corresponding climate controlled floor pens ( 8 replicate floor pens), where they were provided ad libitum feed and water and heated brooding, and were maintained under standard industry temperature and relative humidity settings. The chicks were provided starter, grower, and finisher broiler diets according to standard industry feeding regimens.

\section{Necropsy, and Sample Collection and Analyses}

On each of d 28 and 48 post-hatch, approximately 2 live birds per pen that were hatched from implanted eggs were used for determination of live bird BW and rectal temperature. Subsequently, those birds were euthanized by cervical dislocation and necropsied for determination of sex and for organ collection. Upon necropsy of each bird, the liver, whole breast muscle, and left gastrocnemius muscle were extracted. Subsequently, relative BW (\% of set egg weight), and relative weights ( $\%$ of live bird $\mathrm{BW}$ ) of the liver, and of the breast and gastrocnemius muscles were determined (Keralapurath et al., 2010). In addition, the moisture concentrations (\%) of the liver and of the breast and gastrocnemius muscles were determined by the procedures used by Peebles et al. (1998) and Pulikanti et al. (2010).

\section{Analyses of Tissue Nutrient Profiles}

Immediately after necropsy, a $0.25 \mathrm{~g}$ sample was taken from the liver, breast muscle and gastrocnemius muscle of each bird, and was stored and preserved in a vial containing $10 \%$ perchloric acid. Subsequently, the glucose, glycogen, fat, and protein concentrations of the individual liver, breast muscle and left gastrocnemius muscle samples were analyzed. Tissue glucose and glycogen concentrations were determined using the Phenol-Sulfuric acid method as described by Bennett et al. (2007). Colorimetric protein estimation was accomplished according to Lowry et al. (1951) and colorimetric fat concentration was determined using the methodology of Van Handel (1985). Concentrations of the above tissue variables were expressed as a percentage of fresh sample weight.

\section{Statistical Analysis}

Using the GLM procedure of SAS (2003), partial correlations between pre- and post-hatch variables were generated with data for each individual egg and its corresponding bird. The pre-hatch variables included in the correlation analyses were set egg weight, \% EWL, IL, $\mathrm{T}_{\mathrm{emb}}$, embryonated egg external microenvironment temperature, unfertilized egg internal temperature, incubator dry bulb temperature, incubator data logger temperature, $\mathrm{G}_{\mathrm{H} 2 \mathrm{O}}, \mathrm{g}_{\mathrm{H} 2 \mathrm{O}}$, and $\mathrm{K}_{\mathrm{H} 2 \mathrm{O}}$. The post-hatch variables included in the correlation analyses were relative BW (\% of set egg weight), and relative weights ( $\%$ of live bird $\mathrm{BW})$ and moisture concentrations of the liver, breast muscle, and left gastrocnemius muscle of 28and 48-d-old birds. Partial correlations of the pre-hatch variables with post-hatch variables on $\mathrm{d} 28$ were determined separately from those on $\mathrm{d} 48$. Each individual egg and its corresponding bird were considered as replicate units. The GLM procedure was used to compute the partial correlations in a model that simultaneously fit the variables to be correlated with tray level or floor pen as a fixed effect. The MANOVA statement with the printe option produced the appropriate partial correlations. Partial correlation coefficients were considered significant at $P \leq 0.05$.

\section{Results and Discussion}

Significant partial correlations of pre-hatch physiological variables with various post-hatch growth and tissue variables of the corresponding 28- and 48-d-old birds in the current study are presented in Table 1. Breast muscle moisture concentration on d 28 (BRM28) was negatively correlated with $\mathrm{G}_{\mathrm{H} 2 \mathrm{O}}, \mathrm{g}_{\mathrm{H} 2 \mathrm{O}}$, and $\mathrm{K}_{\mathrm{H} 2 \mathrm{O}}$. However, breast muscle moisture concentration on d 48 (BRM48) was not significantly correlated with $\mathrm{G}_{\mathrm{H} 2 \mathrm{O}}, \mathrm{g}_{\mathrm{H} 2 \mathrm{O}}$, or $\mathrm{K}_{\mathrm{H} 2 \mathrm{O}}$. Embryonic metabolism and internal egg temperature have been shown to increase in response to an increased $\mathrm{G}_{\mathrm{H} 2 \mathrm{O}}$ (Hocking, 2009; French, 1997), and changes in the $\mathrm{K}_{\mathrm{H} 2 \mathrm{O}}$ of an egg affect its rate of water loss during incubation as do changes in incubational relative humidity (Ar et al., 1974). Moreover, an increased embryonic metabolism subsequently increases tissue metabolic water production (Ar and Rahn, 1980), and evaporative moisture loss from an incubating egg is increased by increases in $\mathrm{G}_{\mathrm{H} 2 \mathrm{O}}$ (Ar et al., 1974; Ar and Rahn, 1978). Further, the distribution of water among the various egg and embryonic compartments may be largely influenced by embryo metabolism (Simkiss, 1980).

Based on the information provided by the previous researchers indicated above, it is suggested that an increased rate of water loss during incubation, as reflected by an increased $\mathrm{G}_{\mathrm{H} 2 \mathrm{O}}, \mathrm{g}_{\mathrm{H} 2 \mathrm{O}}$, or $\mathrm{K}_{\mathrm{H} 2 \mathrm{O}}$, may result in a lower BRM28. This would imply that the water budgeting properties of broilers during embryonic life may be carried over into the middle post-hatch period. Although breast muscle moisture concentration was inversely related to $\mathrm{G}_{\mathrm{H} 2 \mathrm{O}}, \mathrm{g}_{\mathrm{H} 2 \mathrm{O}}$, and $\mathrm{K}_{\mathrm{H} 2 \mathrm{O}}$ through $\mathrm{d} 28$, these relationships did not exist through $\mathrm{d} 48$ post-hatch. This suggests that environmental (i.e. water consumption) and physiological (i.e. tissue water retention) factors during the late post-hatch period (d 28 to 48) may 
Table 1. Coefficients and $\boldsymbol{P}$-values for statistically significant $(\boldsymbol{P} \leq \mathbf{0 . 0 5})$ partial correlations of pre-hatch physiological variables of broilers with respective post-hatch physiological variables on $d 28$ and 48 of age

\begin{tabular}{|c|c|c|c|c|c|c|}
\hline Item & $\begin{array}{c}\text { BRM28 } \\
(\%)\end{array}$ & $\begin{array}{c}\text { BW48 } \\
(\%)\end{array}$ & $\begin{array}{c}\text { BRW48 } \\
(\%)\end{array}$ & $\begin{array}{c}\text { BRM48 } \\
(\%)\end{array}$ & $\begin{array}{c}\text { GW48 } \\
(\%)\end{array}$ & $\begin{array}{c}\text { GM48 } \\
(\%)\end{array}$ \\
\hline $\mathrm{T}_{\mathrm{emb}}\left({ }^{\circ} \mathrm{C}\right)$ & - & $\begin{array}{l}{ }^{1}-0.88 \\
\left({ }^{2} 0.05\right)\end{array}$ & $\begin{array}{r}-0.97 \\
(0.01)\end{array}$ & - & - & - \\
\hline $\begin{array}{c}\mathrm{G}_{\mathrm{H} 2 \mathrm{O}} \\
\left(\mathrm{mg} \mathrm{H} \mathrm{H}_{2} \mathrm{O} / \mathrm{d} \times \text { Torr }\right)\end{array}$ & $\begin{array}{r}-0.93 \\
(0.003)\end{array}$ & - & $\begin{array}{c}0.89 \\
(0.04)\end{array}$ & - & - & - \\
\hline $\begin{array}{c}\mathrm{g}_{\mathrm{H} 2 \mathrm{O}} \\
\left(\mathrm{mg} \mathrm{H} \mathrm{H}_{2} \mathrm{O} / \mathrm{d} \times \text { Torr } \times 100 \mathrm{~g}\right)\end{array}$ & $\begin{array}{r}-0.89 \\
(0.01)\end{array}$ & $\begin{array}{c}0.90 \\
(0.04)\end{array}$ & $\begin{array}{c}0.96 \\
(0.01)\end{array}$ & - & - & - \\
\hline $\mathrm{K}_{\mathrm{H} 2 \mathrm{O}}$ & $\begin{array}{r}-0.90 \\
(0.01)\end{array}$ & $\begin{array}{c}0.92 \\
(0.03)\end{array}$ & $\begin{array}{c}0.96 \\
(0.01)\end{array}$ & - & - & - \\
\hline IL (d) & - & $\begin{array}{c}0.95 \\
(0.01)\end{array}$ & - & $\begin{array}{r}-0.93 \\
(0.02)\end{array}$ & $\begin{array}{c}0.88 \\
(0.05)\end{array}$ & $\begin{array}{r}-0.93 \\
(0.02)\end{array}$ \\
\hline
\end{tabular}

\footnotetext{
${ }^{1}$ Correlation coefficient.
}

${ }^{2} P$-value.

$\mathrm{T}_{\mathrm{emb}}$ : Embryonated egg air cell temperature.

$\mathrm{G}_{\mathrm{H} 2 \mathrm{O}}$ : Eggshell water vapor conductance.

$\mathrm{g}_{\mathrm{H} 2 \mathrm{O}}$ : Specific $\mathrm{G}_{\mathrm{H} 2 \mathrm{O}}$.

$\mathrm{K}_{\mathrm{H} 2 \mathrm{O}}: \mathrm{G}_{\mathrm{H} 2 \mathrm{O}}$ constant.

IL: Incubation length.

BRM28: Breast muscle moisture concentration of 28-d-old bird.

BW48: Relative BW (\% of set egg weight) of 48-d-old bird.

BRW48: Relative breast muscle weight (\% of live bird BW) of 48-d-old bird.

BRM48: Breast muscle moisture concentration of 48-d-old bird.

GW48: Relative left gastrocnemius muscle weight (\% of live bird BW) of 48-d-old bird.

GM48: Left gastrocnemius muscle moisture concentration of 48-d-old bird.

influence the relationship between incubational egg water loss and breast muscle moisture. This also suggests that the post-hatch physiological responses of broilers to the prehatch properties of the eggs from which they hatch do not remain the same throughout the post-hatch period, but are highly related to post-hatch age. Therefore, it may not be advisable to make predictions concerning late post-hatch broiler performance in response to various physiological variables during incubation that are based on previous early and middle post-hatch bird performance data.

Mean $\mathrm{T}_{\text {emb }}$ for the 10.5 to $18.5 \mathrm{~d}$ incubation period in the current study was $38.1 \pm 0.05^{\circ} \mathrm{C}$, which indicates that incubation was conducted under normal temperature conditions (Pulikanti et al., 2012a). This also minimized the possibility of abnormal breast muscle development that may result from extremely low or high incubation temperatures. Relative BW (BW48) and breast muscle weight (BRW48) of birds on d 48 post-hatch were negatively correlated with $\mathrm{T}_{\mathrm{emb}}$, suggesting that at a fixed eggshell porosity (i.e., $\mathrm{g}_{\mathrm{H} 2 \mathrm{O}}$ ), an increased $T_{e m b}$ may negatively influence processing yield. However, BW48 and BRW48 were not significantly correlated with incubator dry bulb temperature, the external microenvironment temperature of the embryonated eggs, or with the internal temperature of the unfertilized eggs. This would indicate that it is important to closely and more accurately monitor the internal temperature of embryonated eggs for the estimation of embryonic temperature during incubation in order to optimize broiler processing yield. These findings support the effective use of temperature transponders to determine egg air cell temperature, as a closer estimation of true broiler embryo temperature, as suggested by Pulikanti et al. (2011a, b; 2012a, b) and Peebles et al. (2012).

Furthermore, BW48 and BRW48 were positively correlated with $\mathrm{g}_{\mathrm{H} 2 \mathrm{O}}$ and $\mathrm{K}_{\mathrm{H} 2 \mathrm{O}}$. Similarly, there existed a positive correlation between $\mathrm{G}_{\mathrm{H} 2 \mathrm{O}}$ and BRW48, and a positive correlation between $\mathrm{G}_{\mathrm{H} 2 \mathrm{O}}$ and $\mathrm{BW} 48$ approached significance $(P=0.06)$. These relationships indicate that an improved respiratory functionality of the avian eggshell (i.e., $\mathrm{g}_{\mathrm{H} 2 \mathrm{O}}$ ) to support an increase in embryonic metabolism (Hocking, 2009) and an associated increase in rate of embryogenesis may have a positive influence on subsequent yield at processing age in broilers. Modern strain broilers, such as the ones used in this study, have resulted from intensive genetic selection to reach maximal processing yields at a faster rate (Berri, 2000). Therefore, it is suggested that when embryos of modern strain broilers exhibiting elevated metabolic and growth rates, are encompassed by eggshells that can accommodate these characteristics, that their genetic potential may be more fully realized. This would be subsequently reflected by an increase in processing yield.

The BRM48 and moisture concentration of the gastrocnemius muscle on d 48 were negatively correlated with IL. However, BW48 and relative weight of the gastrocnemius 
muscle of the d 48 bird were positively correlated with IL. This indicates that the birds that hatched after a more prolonged incubation period tended to retain less moisture in their tissues during the late post-hatch period, despite the fact that their relative body and muscle weights were higher compared to the birds that hatched earlier during the incubational period.

The glucose, glycogen, fat, and protein concentrations of the liver, breast muscle, and gastrocnemius muscle on 28 and $48 \mathrm{~d}$ post-hatch were not significantly correlated with their corresponding egg and embryo variables. It is speculated that this may be attributable to possible changes in the nutritional status of the broiler through the middle and late terms of the post-hatch grow-out period, which are largely influenced by various external factors including feed consumption rate and feed conversion efficiency rather than by the corresponding pre-hatch physiological variables examined in this study.

In conclusion, the current results further establish that $\mathrm{T}_{\mathrm{emb}}, \mathrm{G}_{\mathrm{H} 2 \mathrm{O}}, \mathrm{g}_{\mathrm{H} 2 \mathrm{O}}$, and $\mathrm{K}_{\mathrm{H} 2 \mathrm{O}}$ influence embryogenesis during incubation and subsequent broiler processing $\mathrm{BW}$ and breast meat yield. Moreover, these factors may differentially influence various physiological variables in birds during the various phases of the post-hatch grow out period. The initial metabolic and hydration statuses of the birds were negatively influenced by $\mathrm{G}_{\mathrm{H} 2 \mathrm{O}}, \mathrm{g}_{\mathrm{H} 2 \mathrm{O}}$, and $\mathrm{K}_{\mathrm{H} 2 \mathrm{O}}$; however, bird growth, metabolism, and water retention were naturally adjusted later in the post-hatch period to allow bird BW to reach a genetically pre-determined level. Finally, it is apparent that a corresponding increase in $\mathrm{g}_{\mathrm{H} 2 \mathrm{O}}$ may be necessary to accommodate an elevated $\mathrm{T}_{\mathrm{emb}}$, so as to positively influence processing yield. Nevertheless, the close and accurate monitoring of internal egg temperature during incubation is strongly recommended.

\section{Acknowledgments}

We express our appreciation for the expert technical assistance of Dr. Alex Corzo and Sharon K. Womack, and for the assistance of graduate students and undergraduate student workers of the Mississippi State University Poultry Science Department.

\section{References}

Abiola SS, Meshioye OO, Oyerinde BO and Bamgbose MA. Effect of egg size on hatchability of broiler chicks. Archivos de Zootecnia, 57: 83-86. 2008.

Ar A, Paganelli CV, Reeves RB, Greene DG and Rahn H. The avian egg: Water vapor conductance, shell thickness, and functional pore area. Condor, 76: 153-158. 1974.

Ar A and Rahn H. Interdependence of gas conductance, incubational length, and weight of the avian egg. In: Respiratory function in Birds, Adult and Embryonic (Piiper J, ed.). pp. 227-236. Springer-Verlag. Berlin. 1978.

Ar A and Rahn H. Water in the avian egg: overall budget of incubation. American Zoologist, 20: 373-384. 1980.

Bamelis F, Kemps B, Mertens K, De Ketelaere B, Decuypere E and DeBaerdemaeker J. An automatic monitoring of the hatching process based on the noise of the hatching chicks. Poultry
Science, 84: 1101-1107. 2005.

Bennett LW, Keirs RW, Peebles ED and Gerard PD. Methodologies of tissue preservation and analysis of the glycogen content of the broiler chick liver. Poultry Science, 86: 2653-2665. 2007.

Berri C. Variability of sensory and processing qualities of poultry meat. World's Poultry Science Journal, 56: 209-224. 2000.

Bruzual JJ, Peak SD, Brake J and Peebles ED. Effects of relative humidity during incubation on hatchability and body weight of broiler chicks from young breeder flocks. Poultry Science, 79: 827-830. 2000a.

Bruzual JJ, Peak SD, Brake J and Peebles ED. Effects of relative humidity during the last five days of incubation and brooding temperature on performance of broiler chicks from young broiler breeders. Poultry Science, 79: 1385-1391. 2000b.

Celen MF, Yildirim I, Parlat SS and Alkis E. The effects of broiler age and extra oxygen addition into incubator at high altitude $(1700 \mathrm{~m})$ on hatching results and subsequent performance in broilers. Journal of Animal and Veterinary Advances, 8: 1438-1442. 2009.

Everaert N, Kamers B, Witters A, De Smit L, Debonne M, Decuypere E and Bruggeman V. Effects of four percent carbon dioxide during the second half of incubation on embryonic development, hatching parameters, and posthatch growth. Poultry Science, 86: 1372-1379. 2007.

French NA. Modeling incubation temperature: the effects of incubator design, embryonic development, and egg size. Poultry Science, 76: 124-133. 1997.

Hocking PM. (Ed.), Biology of Breeding Poultry, Poultry Science Symposium Series, vol. 29, CABI, Wallingford. Page 208. 2009.

Hulet R, Gladys G, Hill D, Meijerhof R and El-Shiekh T. Influence of egg shell embryonic incubation temperature and broiler breeder flock age on posthatch growth performance and carcass characteristics. Poultry Science, 86: 408-412. 2007.

Keralapurath MM, Keirs RW, Corzo A, Bennett LW, Pulikanti R and Peebles ED. Effects of in ovo injection of L-carnitine on subsequent broiler chick tissue nutrient profiles. Poultry Science, 89: 335-341. 2010.

Leksrisompong N, Romero-Sanchez H, Plumstead PW, Brannan KE and Brake J. Broiler Incubation. 1. Effect of elevated temperature during late incubation on body weight and organs of chicks. Poultry Science, 86: 2685-2691. 2007.

Lourens A, van den Brand H, Meijerhof R and Kemp B. Effect of eggshell temperature during incubation on embryo development, hatchability, and posthatch development. Poultry Science, 84: 914-920. 2005.

Lowry OH, Rosenbrough NJ, Farr AL and Randall RJ. Protein measurement with the folin phenol reagent. The Journal of Biological Chemistry, 193: 265-275. 1951.

Molenaar R, Hulet R, Meijerhof R, Maatjens CM, Kemp B and van den Brand H. High eggshell temperatures during incubation decrease growth performance and increase the incidence of ascites in broiler chickens. Poultry Science, 90: 624-632. 2011a.

Molenaar R, van den Anker I, Meijerhof R, Kemp B and van den Brand $\mathrm{H}$. Effect of eggshell temperature and oxygen concentration during incubation on the developmental and physiological status of broiler hatchlings in the perinatal period. Poultry Science, 90: 1257-1266. 2011b.

Moran Jr ET. Nutrition of the developing embryo and hatchling. Poultry Science, 86: 1043-1049. 2007.

Murakami H, Akiba Y and Horiguchi M. Growth and utilization of 
nutrients in newly-hatched chick with or without removal of residual yolk. Growth, Development, and Aging, 56: 75-84. 1992.

Onagbesan O, Bruggeman V, De Smit L, Debonne M, Witters A, Tona K, Everaert $\mathrm{N}$ and Decuypere E. Gas exchange during storage and incubation of avian eggs: effects on embryogenesis, hatchability, chick quality and post-hatch growth. World's Poultry Science Journal, 63: 557-573. 2007.

Peebles ED, Pansky T, Doyle SM, Boyle CR, Smith TW, Latour MA and Gerard PD. Effects of breeder dietary fat and eggshell cuticle removal on subsequent broiler growout performance. The Journal of Applied Poultry Research, 7: 377-383. 1998.

Peebles ED, Keirs RW, Bennett LW, Cummings TS, Whitmarsh SK and Gerard PD. Relationships among prehatch and posthatch physiological parameters in early nutrient restricted broilers hatched from eggs laid by young breeder hens. Poultry Science, 84: 454-461. 2005.

Peebles ED, Zhai W and Gerard PD. Comparative evaluation of air cell and eggshell temperature measurement methodologies used in broiler hatching eggs during late incubation. Poultry Science, 91: 1536-1541. 2012.

Pinchasov Y. Relationship between the weight of hatching eggs and subsequent early performance of broiler chicks. British Poultry Science, 32: 109-115. 1991.

Pulikanti R, Peebles ED, Keirs RW, Bennett LW, Keralapurath MM and Gerard PD. Pipping muscle and liver metabolic profile changes and relationships in broiler embryos on d 15 and 19 of incubation. Poultry Science, 89: 860-865. 2010.

Pulikanti R, Peebles ED and Gerard PD. Physiological responses of broiler embryos to in ovo implantation of temperature transponders. Poultry Science, 90: 308-313. 2011a.

Pulikanti R, Peebles ED and Gerard PD. Use of implantable temperature transponders for the determination of air cell temperature, eggshell water vapor conductance, and their functional relationships in embryonated broiler hatching eggs. Poultry Science, 90: 1191-1196. 2011b.

Pulikanti R, Peebles ED, Zhai W, Bennett LW and Gerard PD. Embryonic temperature profiles and eggshell water vapor conductance constants in incubating Ross $\times$ Ross 708 broiler hatching eggs. Poultry Science, 91: 55-61. 2012a.
Pulikanti R, Peebles ED, Zhai W, Bennett LW and Gerard PD. Physiological relationships of the early post-hatch performance of broilers to their embryo and eggshell characteristics. Poultry Science, 91: 1552-1557. 2012b.

SAS Institute. SAS Proprietary Software. Release 9.1. SAS Inst. Inc., Cary, NC. 2003.

Simkiss K. Water and ionic fluxes inside the egg. American Zoologist, 20: 385-393. 1980.

Tullett SC and Burton FG. Factors affecting the weight and water status of the chick at hatch. British Poultry Science, 23: 361-369. 1982.

van de Ven LJF, van Wagenberg AV, Debonne M, Decuypere E, Kemp B and van den Brand $\mathrm{H}$. Hatching system and time effects on broiler physiology and posthatch growth. Poultry Science, 90: 1267-1275. 2011.

Van Handel E. Rapid determination of total lipids in mosquitoes. Journal of the American Mosquito Control Association, 1: 302-304. 1985.

Vieira SL and Moran ET. Effects of egg of origin and chick posthatch nutrition on broiler live performance and meat yields. World's Poultry Science Journal, 55: 125-142. 1999.

Willemsen H, Li Y, Willems E, Franssens L, Wang Y, Decuypere E and Everaert N. Intermittent thermal manipulations of broiler embryos during late incubation and their immediate effect on the embryonic development and hatching process. Poultry Science, 90: 1302-1312. 2011.

Willemsen H, Tona K, Bruggeman V, Onagbesan O and Decuypere E. Effects of high $\mathrm{CO}_{2}$ level during early incubation and late incubation in ovo dexamethasone injection on perinatal embryonic parameters and post-hatch growth of broilers. British Poultry Science, 49: 222-231. 2008.

Wolanski NJ, Renema RA, Robinson FE, Carney VL and Fancher BI. Relationships among egg characteristics, chick measurements, and early growth traits in ten broiler breeder strains. Poultry Science, 86: 1784-1792. 2007.

Yalcin S, Ozkan S, Cabuk M, Buyse J, Decuypere E and Siegel PB. Pre- and postnatal conditioning induced thermotolerance on body weight, physiological responses and relative asymmetry of broilers originating from young and old breeder flocks. Poultry Science, 84: 967-976. 2005. 